\title{
ESTUDO TRIBOLÓGICO DE ÓLEOS BIODEGRADÁVEIS DE COCO E DE RÍCINO ATRAVÉS DE ENSAIOS ABRASIVOS
}

\author{
Jaciana Silva de Santana \\ Universidade Federal do Rio Grande do Norte.E-mail: jaciana_santana@yahoo.com.br \\ Aline Cristina Mendes de Farias \\ Universidade Federal do Rio Grande do Norte. E-mail: alinecmfarias@ufrnet.br \\ Janaina Silva de Santana \\ Universidade Federal do Rio Grande do Norte. E-mail: jana_materiais@yahoo.com.br \\ Cleiton Rubens Formiga Barbosa \\ Universidade Federal do Rio Grande do Norte. E-mail: cleiton@ufrnet.br \\ João Telésforo Nóbrega de Medeiros \\ Universidade Federal do Rio Grande do Norte. E-mail: jtelesforo@yahoo.com
}

\section{RESUMO}

Os óleos podem ser de duas origens diferentes, biológicos e não biológicos, e este fornece uma vasta gama de compostos de hidrocarbonetos. Estas substâncias estão geralmente presentes em misturas complexas e podem ser usadas para muitas outras finalidades além de lubrificação, que é o controle do desgaste e atrito. A moderna tecnologia coloca exigências severas e variadas aos lubrificantes, assim como a seleção e a formulação de misturas de hidrocarbonetos adequados para fins de lubrificação é um processo especializado e complexo. Em substituição aos óleos minerais, os óleos biodegradáveis vêm proporcionando uma grande alternativa ao mercado, uma vez que o mesmo diminui os impactos ambientais. Com a finalidade de avaliar o desempenho do óleo de rícino (refinado e bruto) e o óleo de coco comparando-os com os óleos minerais SAE 20W50 SJ e W40, realizaram-se ensaios tribológicos de desgaste na configuração pino-contra-cilindro de aço AISI 52100. As superfícies das amostras metálicas foram confeccionadas por torneamento e lixamento, utilizando-se lixas de diferentes granulometrias, seguidas por limpeza com banho ultrassônico e pesagem antes e após a realização dos ensaios. Os corpos-de-prova foram analisados antes dos ensaios no microscópio óptico. A dureza do aço AISI 52100 foi medida utilizando-se um durômetro Rockwell. O óleo foi caracterizado através de ensaios de densidade e tensão superficial. A eficiência da ação do lubrificante foi avaliada através da taxa de desgaste calculada para as amostras utilizando-se a equação de Archard e através da microscopia eletrônica de varredura (MEV). Segundo resultados da taxa de desgaste, os óleos vegetais de rícino e coco obtiveram valores de 88,89\% e $33,33 \%$ menores que para os óleos W40 e SAE 20W50 SJ, respectivamente. Sendo assim, os óleos vegetais possuem propriedades tribológicas equivalentes e até superiores às dos óleos minerais estudados.

PALAVRAS-CHAVE: óleo de rícino, óleo de coco, lubrificação, desgaste, tribologia 
TRIBOLOGY STUDY OF BIODEGRADABLE OILS (COCONUT AND CASTOR) FROM TESTING ABRASIVE

\begin{abstract}
Oils can be of two different origins, biological and non-biological, and this provides a vast array of hydrocarbon compounds. These substances are usually present as complex mixtures and can be used for many other purposes besides lubrication, that is the control of wear and friction. Modern technology places severe and varied demands on lubricants, so the selection and formulation of appropriate mixtures of hydrocarbons for the purposes of lubrication is a skilled and complex process. Replacing mineral oils, biodegradable oils have been providing a great alternative to the industrial market, since it reduces environmental impacts. In order to evaluate the performance of ricin oil (crude and refined) coconut oil and comparing them with mineral oil SAE 20W50 SJ and W40, tribological wear tests were performed using the steel AISI 52100 pin-on-cylinder configuration. The surfaces of metallic samples were prepared by turning and sanding, using sandpaper of different grain sizes, followed by ultrasonic cleaning bath and weighing before and after the tests. The coupons (pins) used in evidence before the tests were analyzed in the optical microscope. The hardness of the AISI 52100 steel was measured using a Rockwell hardness test. The oils were characterized by testing the density and surface tension. The efficiency of action of the lubricant was evaluated through the calculated wear rates for the coupons using Archard's equation and by scanning electron microscopy (SEM). According to results of the wear rates, the vegetable oils such as castor oil and unrefined coconut obtained values of $88.89 \%$ and $66.67 \%$ lower than for the oils and SAE 20W50 SJ W40, respectively. Therefore, the vegetable oils have similar or superior tribological properties than for the studied mineral oils.
\end{abstract}

KEYWORDS: ricin oil, coconut oil, lubrication, wear, tribology 


\section{ESTUDO TRIBOLÓGICO DE ÓLEOS BIODEGRADÁVEIS DE COCO E DE RÍCINO ATRAVÉS DE ENSAIOS ABRASIVOS}

\section{INTRODUÇÃO}

Os combustíveis fósseis são recursos exauríveis e a busca por recursos renováveis é cada vez mais importante para garantir a segurança energética e a proteção ambiental [AGARWAL Et. Al. (2008) Apud FARIAS Et. Al. (2010)]. Uma das formas de reduzir os impactos causados por estes óleos é promover a sua substituição por óleos vegetais biodegradáveis.

Os lubrificantes feitos a partir de óleos naturais ou minerais são parcialmente refinados e parcialmente impura. O equilíbrio entre a impureza e a pureza é fundamental para a estabilidade a oxidação do óleo e que varia dependendo da aplicação do lubrificante. Os produtos químicos que são deliberadamente adicionado a um óleo para melhorar suas propriedades são chamados aditivos. Aditivos podem mudar radicalmente as propriedades de um lubrificante e são essenciais para o seu desempenho global. Eles também ditam as características específicas do lubrificante como a tendência à corrosão, formação de espuma, oxidação, coagulação, desgaste, atrito e outras propriedades (STACHOWIAK e BATCHELOR, 1996).

Os óleos minerais são os lubrificantes obtidos a partir de petróleo e sua é muito complexa. A maior parte dos óleos minerais, constituída por hidrocarbonetos com cerca de 30 átomos de carbono em cada molécula. A estrutura de cada molécula é composta de várias cadeias alifáticas (lineares) unidas a cadeias carbônicas cíclicas. Em conseqüência, não é possível dar uma análise precisa de óleo mineral, o estudos de desgaste e atrito em contatos lubrificados estão sendo conduzidos na presença de fluidos orgânicos puros de composição conhecida como hexadecano. (STACHOWIAK e BATCHELOR, 1996).

O fenômeno de desgaste é comum na maioria dos elementos e dispositivos mecânicos e, em boa parte das aplicações, pode ser o fator determinante na quantificação da sua vida em serviço (REIS e SAVAGLIA, 1999). Ele é caracterizado como uma perda progressiva de material devido ao contato entre duas superfícies que apresentam movimento relativo entre si (HUTCHINGS, 1992). Segundo Dušan (2003), o valor do desgaste dos elementos de um sistema tribológico depende de fatores como carga externa, velocidade de deslizamento, tipo de lubrificante, etc.

O desgaste por abrasão ocorre quando dois corpos possuem movimentos relativos entre si e quando a dureza de um material é superior a $20 \%$ da dureza do outro. Na grande maioria dos sistemas que utilizam engrenagens, é necessária a aplicação de lubrificante, os quais têm a função de introduzir entre as superfícies de deslizamento uma camada de material com resistência ao cisalhamento menor que a das superfícies em contato (HUTCHINGS, 1992).

A deformação plástica é decorrente do desgaste abrasivo. No desgaste por abrasão são identificados mecanismos de corte, sulcamento (riscos abrasivos) e formação de proa (acúmulo de material fora da zona de contato, sendo estes dependentes da geometria do contato e da dureza do par tribológico), além da formação de filme óxido quando, por exemplo, trata-se de um contato não-lubrificado. Outros tipos de mecanismos de desgaste 
são a deformação plástica, a qual é decorrente do fluxo plástico de material, e delaminação, ou seja, formação de lâminas finas na proa de desgaste (LIMA DA SILVA, 2010).

Durante o deslocamento relativo entre duas superfícies, deve-se aplicar uma força suficientemente grande para vencer a resistência ao atrito e, com a continuidade do deslizamento, essa força deve ser mantida e, desse modo, é injetada energia no sistema. Além da manutenção do deslizamento entre as superfícies, esta energia pode ser utilizada de vários modos, os quais sejam a deformação de partículas de desgaste, emissão de energia acústica e calor (SANTANA, 2005).

Em alguns sistemas lubrificados, o lubrificante pode não prevenir completamente o contato entre as asperezas, entretanto, também pode reduzir a resistência da formação de junções (soldagem mecânica). Em outros casos, o lubrificante separa as superfícies completamente e nenhuma junção é formada (HUTCHINGS, 1992).

Este estudo trata-se de uma investigação preliminar do comportamento tribológico de óleos biodegradáveis de coco e de rícino para aplicações como lubrificantes.

\section{MATERIAIS E PROCEDIMENTO EXPERIMENTAL OBTENÇÃO DOS CORPOS-DE-PROVA E CONTRACORPOS}

Para a realização do ensaio tribológico de abrasão, corpos-de-prova planos (pinos) e contracorpos cilíndricos de aço AISI 52100 (aço rolamento) foram usinados pelo processo de torneamento, obtendo-se a geometria ilustrada na Figura 1. As dimensões dos corposde-prova foram de $14,20 \mathrm{~mm}$ de altura e $12,25 \mathrm{~mm}$ de diâmetro, enquanto que os contracorpos apresentaram as dimensões de $12,25 \mathrm{~mm}$ de espessura e $24,5 \mathrm{~mm}$ de diâmetro.

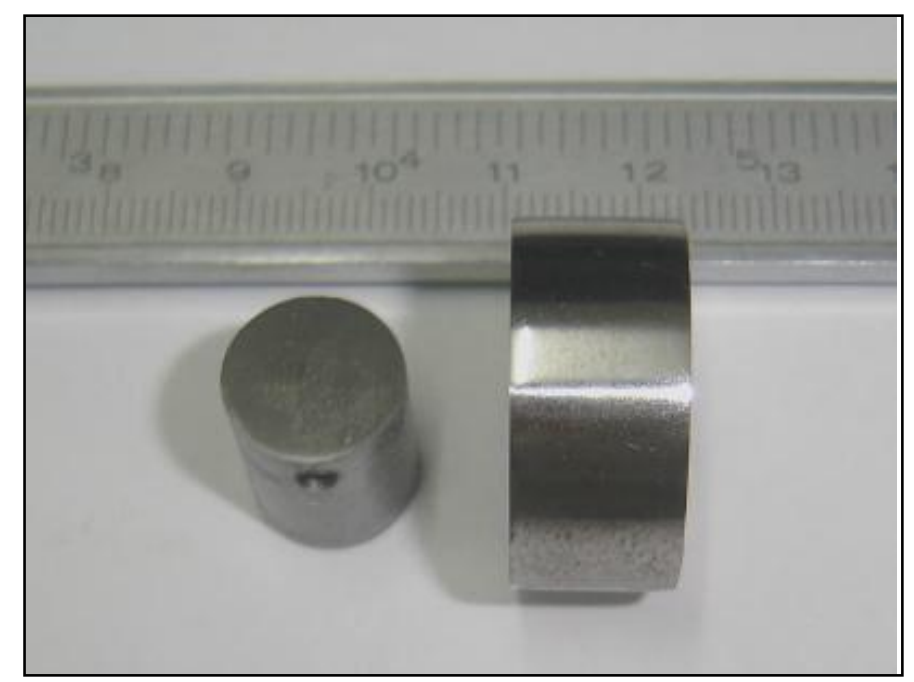

Figura 1 - Geometria dos corpos-de-prova (pino) e contracorpos cilíndricos de aço AISI 52100

O acabamento das superfícies dos corpos-de-prova e contracorpos após a usinagem foi obtido com a utilização de lixas de $\mathrm{SiC}$ nas seguintes granulometrias: \#100, \#180, \#240, \#360, \#400, \#600 e \#1200. Após o lixamento, eles foram submetidos a banho ultrassônico por 20 minutos numa solução de álcool isopropílico, sendo sua secagem promovida pelo 
uso de secador. Após estes procedimentos, os corpos-de-prova foram analisados por microscopia óptica antes da realização dos ensaios de tribológicos de desgaste para certificação de sua uniformidade superficial.

\section{ENSAIO DE DUREZA ROCKWELL PARA O AÇO AIS 52100}

A dureza do aço utilizado na confecção das amostras foi verificada através de ensaios de dureza Rockwell B utilizando-se o durômetro Panambra ${ }^{\circledR}$ com indentador esférico de aço aplicando-se uma pré-carga de $10 \mathrm{Kgf}$ e carga de $100 \mathrm{Kgf}$. O valor de $89 \pm 0,49 \mathrm{HRB}$ foi obtido a partir de um total de sete medições (valor de dureza do aço AISI 52100 nãotratado termicamente.).

\section{RUGOSIDADE SUPERFICIAL}

A rugosidade superficial dos corpos-de-prova e contracorpos foram avaliadas através de um rugosímetro portátil Figura 2, no sentido transversal ao lixamento final. $\mathrm{O}$ comprimento de amostragem, ou cutoff $(\lambda \mathrm{c})$, foi de $0,8 \mathrm{~mm}$. Todas as amostras foram submetidas a sete repetições de ensaio para possibilitar uma varredura mais confiável de sua superfície.

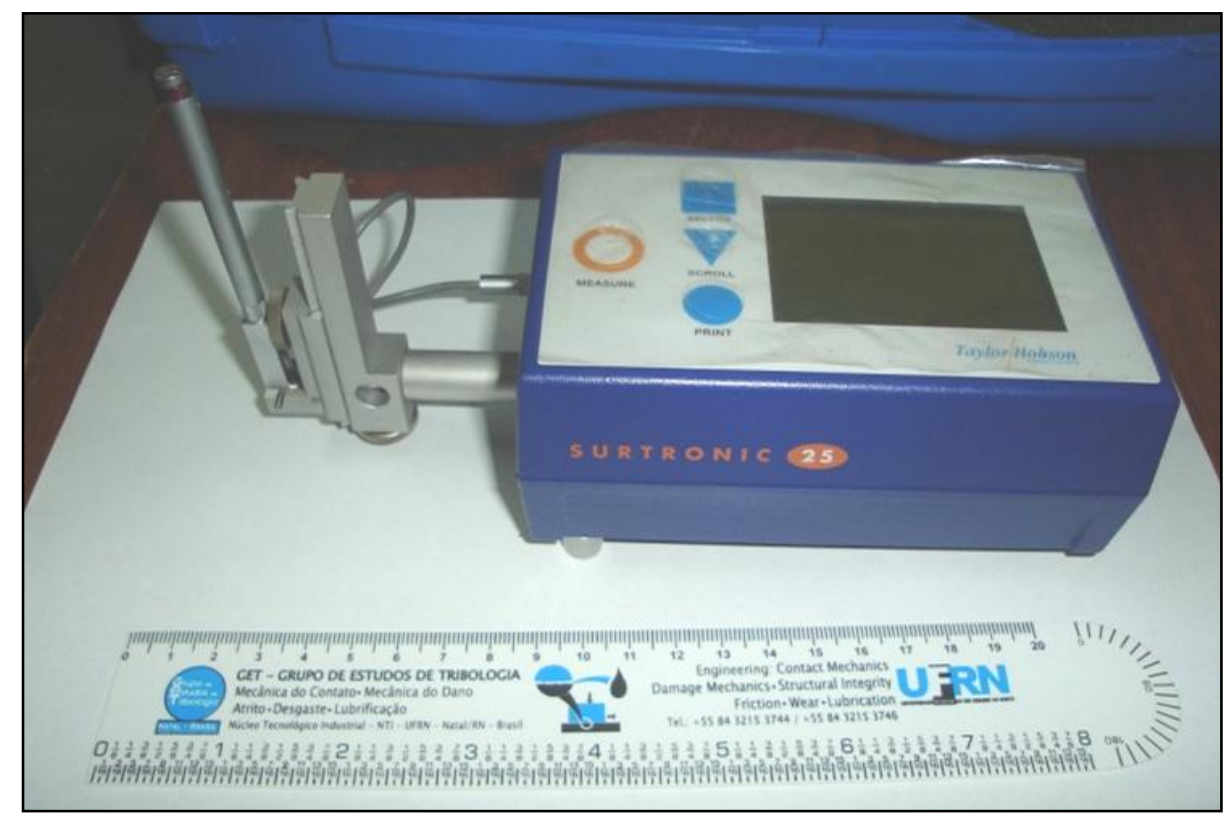

Figura 2 - Rugosímetro portátil Taylor Hobson ${ }^{\circledR}$ Precision Surtronic 25

\section{CARACTERÍSTICAS DOS LUBRIFICANTES: DENSIDADE E TENSÃO SUPERFICIAL}

Tanto os óleos vegetais de coco e de rícino, quanto os minerais 20W50 SJ e SAE W40, foram adquiridos comercialmente e submetidos a ensaios de densidade e tensão superficial, utilizando-se um tensiômetro (Krüss ${ }^{\circledR}$ - Processor Tensiometer K100). 


\section{ENSAIO TRIBOLÓGICO DE DESGASTE}

Antes da realização do ensaio tribológico de desgaste são necessários efetuar a pesagem dos corpos-de-prova através do uso da balança digital (Sartorius CC1201) e; a medida dos desvios de batida radial nas superfícies dos contracorpos cilíndricos utilizando-se um relógio comparador.

Os ensaios tribológicos de desgaste foram realizados em condições lubrificadas com óleos vegetais de rícino e coco não-refinados, rícino refinado e para os óleos minerais 20W50 SJ e W40. Sendo estes óleos minerais utilizados como referência.

Na figura 3 é ilustrado o esquema do aparato experimental de um tribômetro adaptado a partir de um torno de bancada. Neste uma superfície de revolução cilíndrica desliza em contato com uma superfície plana do corpo-de-prova (fixado ao porta-amostra), onde uma carga normal e constante de 5,22 $\mathrm{N}$ é aplicada utilizando-se um peso morto mantendo assim as superfícies em contato. A distância total de deslizamento foi de $10 \mathrm{~km}$ a uma velocidade rotacional de $817 \mathrm{rpm}$ para o contracorpo cilíndrico.

Com base no esquema abaixo Figura 3, o fluxo de óleo é controlado através de uma válvula reguladora e a temperatura é coletada utilizando-se dois sensores termopares, os quais são acoplados à placa de aquisição de dados (National Instruments ${ }^{\circledR}$ ). Para tanto, um termopar é fixado a aproximadamente $3 \mathrm{~mm}$ da superfície do corpo-de-prova plano, e o outro é posicionado a uma distância de $400 \mathrm{~mm}$ do par pino-cilindro para a coleta da temperatura ambiente.

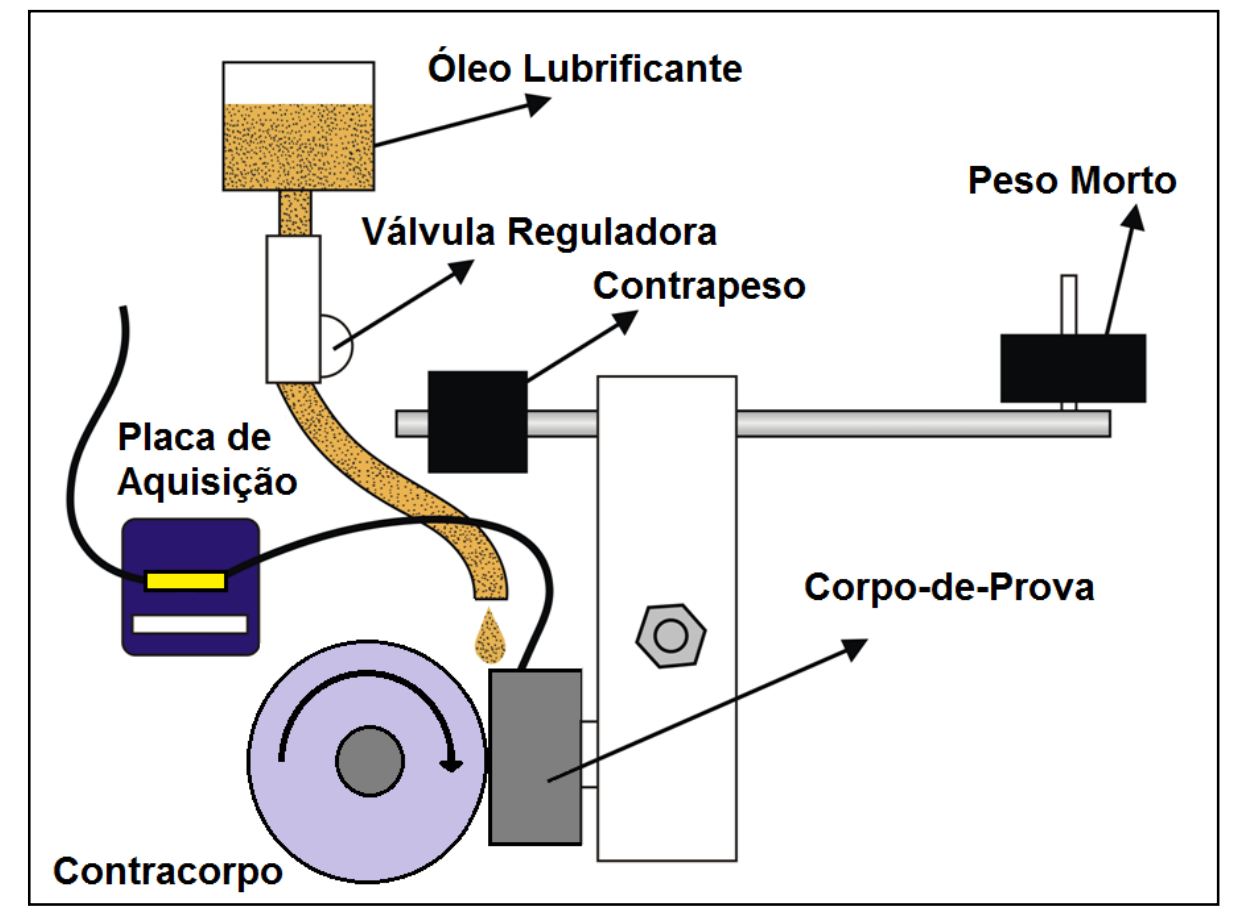

Figura 3 - Esquema da configuração dos ensaios de tribológico de desgaste

Para o cálculo da taxa de desgaste foram necessárias a limpeza e pesagem também após a realização dos ensaios tribológicos. A taxa de desgaste dos corpos-de-prova foi calculada através da equação de Archard (HUTCHINGS, 1992), onde o coeficiente de desgaste adimensional (K) é encontrado através da expressão Equação 1 abaixo: 


$$
Q=\frac{K W}{H}
$$

onde:

Q simboliza o volume desgastado por unidade de distância de deslizamento $\left(\mathrm{mm}^{3} / \mathrm{m}\right)$ a relação $\mathrm{K} / \mathrm{H}(\mathrm{H}=$ dureza do material mais mole) é simbolizada por ka (coeficiente de desgaste dimensional, $\mathrm{m}^{2} / \mathrm{N}$ ) e $\mathrm{W}$, a carga normal aplicada dada em Newton.

A equação 2 a seguir, é mais utilizada em aplicações de engenharia (HUTCHINGS, 1992). Logo, a Equação 1 pode ser escrita da seguinte forma:

$$
k_{a}=\frac{Q}{W}
$$

Após a execução dos ensaios tribológicos de desgaste, as superfícies dos corpos-de-prova foram avaliadas por microscopia eletrônica de varredura (MEV) para identificação dos principais mecanismos de desgaste atuantes no sistema pino-contra-cilindro.

\section{RESULTADOS E DISCUSSÃO}

\section{RUGOSIDADE SUPERFICIAL}

A média e o desvio padrão dos valores de rugosidade são apresentados na Tabela 1.

Tabela 1. Valor médio e desvio padrão das médias de rugosidade

\begin{tabular}{|c|c|c|c|}
\hline \multirow{2}{*}{ Materiais } & \multicolumn{3}{|c|}{ Rugosidade $(\boldsymbol{\mu m})$} \\
\cline { 2 - 4 } & $\mathbf{R a}$ & $\mathbf{R q}$ & $\mathbf{R z}$ \\
\hline Corpos-de-prova planos & $0,22 \pm 0,11$ & $0,27 \pm 0,14$ & $1,20 \pm 0,62$ \\
\hline Contracorpos cilíndricos & $0,23 \pm 0,09$ & $0,30 \pm 0,11$ & $1,78 \pm 0,49$ \\
\hline
\end{tabular}

\section{CARACTERÍSTICAS DOS LUBRIFICANTES: DENSIDADE E TENSÃO SUPERFICIAL}

Os respectivos valores são dados na Tabela 2.

Tabela 2. Resultados de densidade e de tensão superficial para os óleos estudados

\begin{tabular}{|l|c|c|}
\hline \multicolumn{1}{|c|}{ Tipos de Óleos } & $\begin{array}{c}\text { Densidade } \\
(\mathbf{g} / \mathbf{m L})\end{array}$ & $\begin{array}{c}\text { Tensão Superficial } \\
(\mathbf{m N / m})\end{array}$ \\
\hline Coco & 0,918 & $24,64 \pm 0,28$ \\
\hline Rícino bruto & 0,957 & $33,32 \pm 0,03$ \\
\hline Rícino refinado & 0,956 & $31,97 \pm 0,06$ \\
\hline SAE 20W50 SJ & 0,890 & $31,10 \pm 0,06$ \\
\hline W40 & 0,874 & $30,96 \pm 0,04$ \\
\hline
\end{tabular}




\section{VARIAÇÃO DE TEMPERATURA}

A variação de temperatura é um parâmetro utilizado como medida indireta do atrito gerado. Na Figura 4 é apresentado o gráfico da diferença entre a temperatura a $3 \mathrm{~mm}$ do contato pino-cilindro (Tc) e a temperatura ambiente (Ta) em função da distância de deslizamento.

Observa-se no gráfico abaixo Figura 4, que no ensaio tribológico de desgaste lubrificado por óleo de rícino bruto houve maior aquecimento na região de contato que para os demais. Estes, por sua vez, apresentaram praticamente a mesma variação de temperatura até aproximadamente $6 \mathrm{~km}$ de distância de deslizamento, após esta posição houve uma pequena ascendência de temperatura (Tc-Ta) para os ensaios utilizando os óleos de rícino refinado e o 20W50 SJ. Observa-se que a variação de temperatura dos óleos de coco e do W40 foi menor.

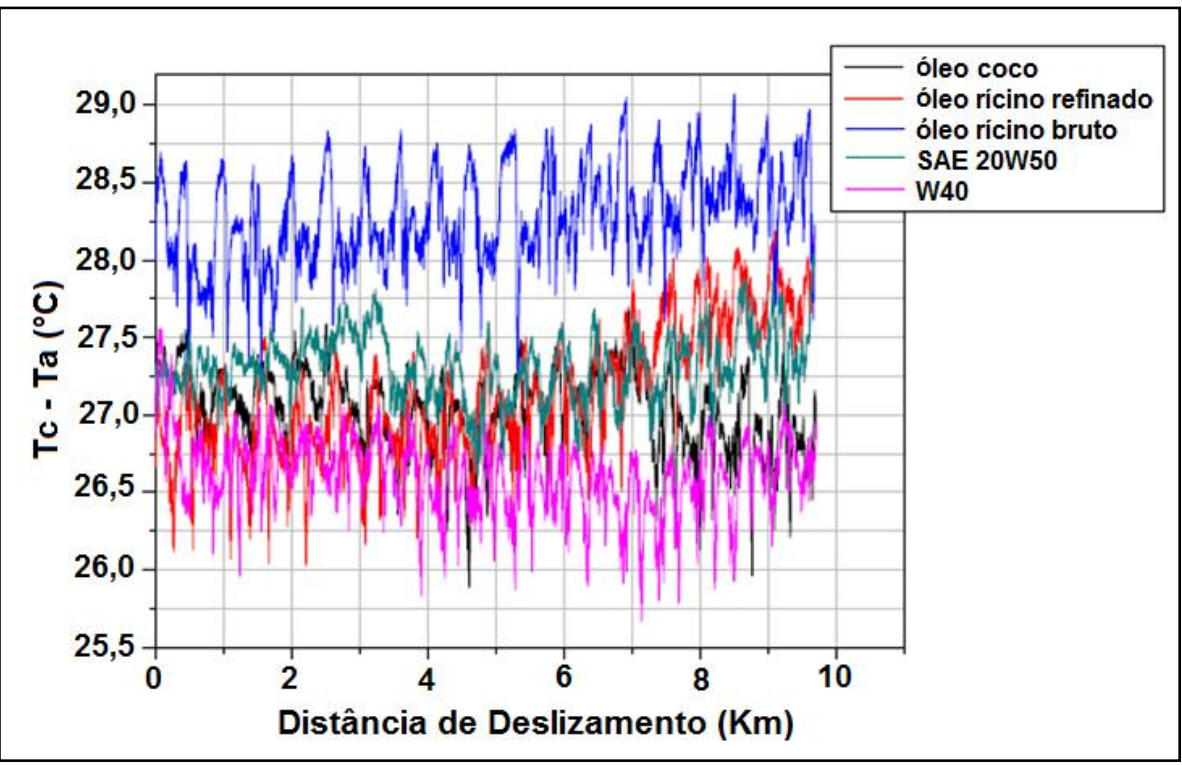

Figura 4 - Gráfico da variação de temperatura em função da distância de deslizamento

\section{TAXA DE DESGASTE}

Os resultados da taxa de desgaste, obtidas a partir da pesagem dos corpos-de-prova antes e após os ensaios de tribológicos, são mostrados no gráfico da Figura 5. 
SANTANA et al (2010)

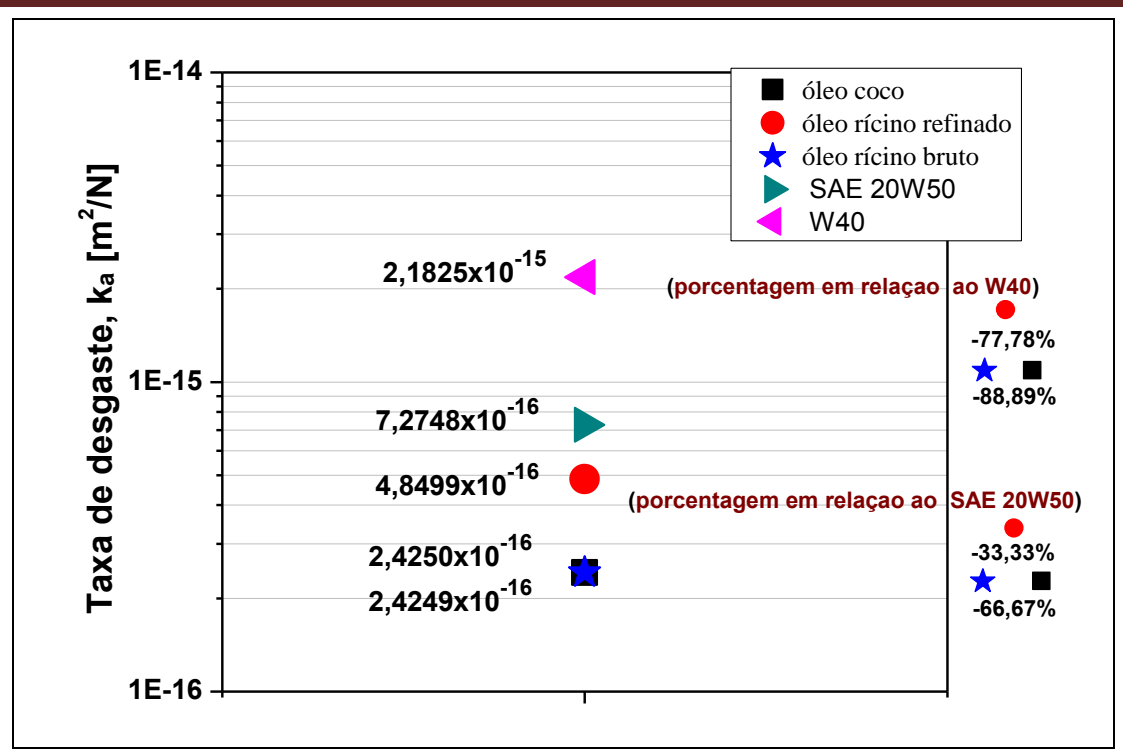

Figura 5 - Gráfico da taxa de desgaste calculada após ensaios tribológicos de desgaste para os óleos avaliados

Com base na Figura 5, as taxas de desgaste calculadas para os óleos vegetais foram menores que para os óleos minerais estudados, principalmente para os óleos de coco e de rícino não-refinados, os quais obtiveram conjuntamente percentuais de 88,89\% e $66,67 \%$ menores que os óleos lubrificantes W40 e 20W50 SJ, respectivamente. Já o óleo de rícino refinado obteve percentuais de $77,78 \%$ e $33,38 \%$ menores em relação aos respectivos óleos minerais.

\section{ANÁLISE DOS MECANISMOS DE DESGASTE POR MEV}

As imagens das superfícies desgastados dos corpos-de-prova são apresentadas na Figura 6. Estas foram obtidas através de microscopia eletrônica de varredura (MEV), onde as setas indicam a direção e o sentido do deslizamento ocorrido durante o ensaio tribológico de desgaste.

Analisando-se as superfícies desgastadas da Figura (6a-6e), observa-se que os corpo-deprova lubrificados com óleo de coco e rícino bruto apresentaram superfícies de desgaste menos danificadas que as superfícies dos demais óleos; sendo o sulcamento (riscos abrasivos), deformação plástica (decorrente do fluxo plástico de material) e delaminação (formação de lâminas finas na proa de desgaste) identificados como os principais mecanismos de desgaste ocorridos. 

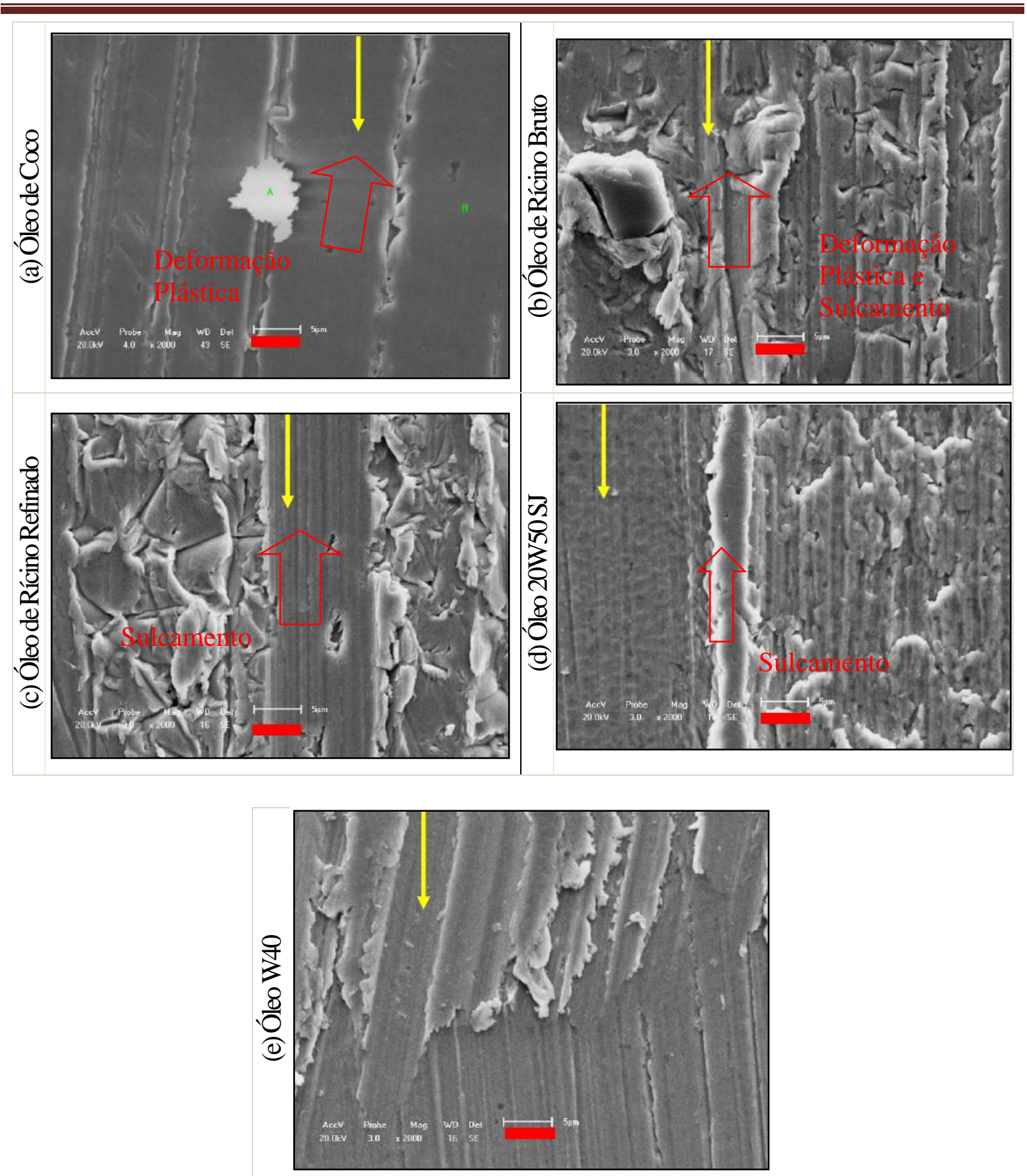

Figura 6 - MEV das superfícies planas desgastadas nas condições de lubrificação com: (a) óleo de coco; (b) óleo de rícino bruto; (c) óleo de rícino refinado; (d) óleo SAE 20W50 SJ e (e) óleo W40

\section{CONCLUSÕES}

O mundo busca uma alternativa de energias limpas, com o intuito de diminuir a degradação do meio ambiente e a independência dos recursos exauríveis. Com isso, a possibilidade da utilização dos óleos vegetais biodegradáveis em substituição aos óleos minerais torna-se uma alternativa promissora.

Do ponto de vista tribológico, o estudo mostrou que os óleos vegetais "in natura" possuem características superiores aos óleos minerais, no entanto é necessário é necessário 
aprimorar suas características físico-químicas, como por exemplo seu índice de saponificação e acidez.

O ensaio tribológico de desgaste é uma ferramenta que satisfaz a caracterização tribológica do óleo com relação a sua aplicação em sistemas dinâmicos. Os resultados da taxa de desgaste obtidos indicaram que os óleos vegetais apresentaram melhor desempenho quanto a propriedade de lubrificar o sistema, os quais oferecem percentuais de taxa de desgaste de 33,33 a 88,89 \% menores que as obtidas para os óleos minerais W40 e SAE 20EW50 SJ. De acordo com estes resultados, os óleos vegetais de rícino e de coco possuem características lubrificantes superiores aos óleos minerais estudados.

Os resultados de diferença de temperatura (Tc-Ta) indicam que ouve maior atrito para o ensaio lubrificado com o óleo de rícino bruto. Sendo que os demais forneceram variações térmicas aproximados até os primeiros $6 \mathrm{Km}$ de distância de deslizamento, onde houve aumento de temperatura para os óleos de rícino refinado e SAE 20W50 SJ.

De acordo com as imagens das superfícies desgastadas dos pinos de aço AISI 52100, foi possível identificar os mecanismos de desgaste de sulcamento, deformação plástica e delaminação. As superfícies lubrificadas, com óleo de coco e rícino bruto, foram as que apresentaram menos danos superficiais e/ou perda de material.

\section{REFERÊNCIAS}

1. DUSAN, J. Tribological properties of isothermally upgraded nodular cast iron in contact with carbon steel and grey pig-iron casting. National Tribology Conference, 2003.

2. FARIAS, A. C. M.; SANTANA, J.S.; SANTANA, J.S, OLIVEIRA FILHO, M.F.; BARBOSA, C.R.F.; MEDEIROS, J.T.N. Os combustíveis verdes do Brasil avaliação da lubricidade do óleo biodiesel B5 e óleos vegetais de coco e mamona. Anais do IV Congresso Nacional de Engenharia Mecânica, Campina Grande, PB, 2010 .

3. HUTCHINGS, I.M. Tribology: friction and wear of engineering materials. University of Cambridge, 1992.

4. LIMA DA SILVA, R.C. Desgaste de polímeros estruturais de engenharia em contato de deslizamento com cilindro metálico. Tese de doutorado apresentada na Universidade Federal do Rio Grande do Norte, Brasil, 2010.

5. REIS e ZAVAGLIA. Projetos e construção de um equipamento para ensaios de desgaste de materiais para uso em próteses ortopédicas, Revista Brasileira de Engenharia Biomédica, vol. 15, 1999.

6. SANTANA, J. S. - Desgaste de cerâmicas com resíduos de granito, através do contato com esferas de vidro, esferas de aço e poliuretano. Monografia apresentada na Universidade Federal do Rio Grande do Norte, Brasil, 2005.

7. SOUZA, L.D., NUNES, A.O., SANTOS, A.G.D., BARROS NETO, E.L. Caracterização padronizada de óleos, diesel e biodiesel produzidos ou consumidos no RN. Química do Brasil, vol1 n², 2007.

8. STACHOWIAK, G.W.; BATCHELOR, A.W. Engineering Tribology. Ed. Butterworth-Heinemann, 1996, 769 p. 